\title{
Application of Blockchain-Based technology for Smart Transport System
}

\author{
Katkova M.A.* \\ Yuri Gagarin State Technical University of Saratov \\ Saratov, Russia \\ e-mail:mkatkova@mail.ru
}

Kapustina N.V.

Russian University of Transport (MIIT)

Russian New University

Moscow, Russia

e-mail: kuzminova_n@mail.ru

\author{
Tregubov V.N. \\ Yuri Gagarin State Technical University of Saratov \\ Saratov, Russia \\ e-mail: tregubovvn@outlook.com
}

\author{
Pilipchuk N.V. \\ Tver State University \\ Tver, Russia \\ e-mail: nadezda.pilipchuk@gmail.com
}

\begin{abstract}
The article discusses applications of the blockchainbased technology in a smart transport system (STS). We proposed to represent the urban transport system as a complex system with the interaction between some stakeholders, where each stakeholder has own purposes and opportunities and can resolve it with the blockchain-based technology. We proposed a method of assessing the investment risks of initial coin offer (ICO) for transport companies. We also have developed the algorithm of investment projects risk analysis in crypto technology sector. There are some examples of blockchain implementations in the smart transport systems, we made the comparative study of some blockchain-based transportation projects, and classification of investment risks in transport projects.
\end{abstract}

Keywords - urban transport system, innovation, blockchain, initial coin offer (ICO).

\section{INTRODUCTION}

We live in a populated, urban and connected world, so we need to use more effective transportation technologies. Some shifts are evidently taking place across some regions and industries. From developments of new public transportation system in Russia to autonomous trucks and self-driving cars in European countries, there are rapid changes in transport sectors. The smart mobility [1] is a concept of modern, more connected and efficient transport system which is both timely and relevant for many. A smart mobility system can use some blockchain-based technologies. Blockchain is a distributed database that is built according to certain rules and contains a sequential chain of blocks which store useful information. Each block has a timestamp when it is created and the link to the previous block. All blocks are secured by the algorithm. Cryptographic algorithms enforce rules for adding new blocks to the chain and allow the tracking of all changes in existing blocks to ensure their integrity and immutability. This approach is called a distributed lager and it created a decentralized structure which has no single regulator that could dispose of the blocks on their own.

\section{MATERIALS AND METHODS}

Blockchain is a database without centralized control; it is open for adding data or for receiving it for any member. Storage of information is carried out on the computers of participants. Researchers highlight some shortcomings of the blockchain-based technology: need to store a copy of all data for each participant and to store the history of all changes, it requires large capacity of storage. Keeping a complete history of changes leads to rapidly storage increasing follow by the number of participants. A higher number of participants also increase the time of operations and the cost of a single operation. Blockchain technology uses different types of resources, in particular, electricity and investment in equipment. Currently, there are various use cases of Blockchain technology is the most known method is the implementation of cryptocurrency as a financial instrument, without the participation of the government.

Distributed Ledger technology (DLT) [2] allows creating custom solutions for real-time tracking and analyzing financial flows and visualizing them. This technology uses a common digital register and continuous integration of all transactions. The decentralized transaction log keeps all transactions that occur with the product during its transportation.

Smart transport is a good object for the implementation of the blockchain-based technology. The benefits of the digital technologies in smart transport are well known and most of modern transport technologies are based on using of information and communications technologies [3, 4]. Indeed, 
the Blockchain technology has many advantages: it allows creating a self-organized transport system with the automated interactions between the stakeholders of the transport system. The prospects of the Blockchain technology are also in the realization of the internet of things (IoT) and autonomous logistics [5-9], when smart vehicles can autonomously choose routes.

There are some successful examples of the Blockchain technology implementation in the smart transport. The Ryder company [10] uses the Blockchain technology for storage of the truck drivers' reports. These reports contain information about the current technical condition of the vehicle and its technical maintenance. The company keeps a complete history of trips and maintenance operations throughout the car life cycle in the distributed lager. It allows solving the problem of storing information without a centralized database and registered the information about cars. Users can be guaranteed that the history of the car has not been amended; the car is in good condition and maintenance operations have been done on time, it adapts for specific types of goods and it has already performed similar transportations in the past.

IBM transport portal [11] identifies a group of projects which can be implemented with the Blockchain technology:

- using a distributed register to securely store information about maintenance and repairs and used spare parts on the vehicle;

- creation of a new type of loyalty programs based on the distributed ledger which stores all the information about participation and creates a highly transparent environment for all participants;
- reducing of the paper documents and replacing them with electronic documents, it increases the degree of security.

The technology of a distributed ledger is currently at the stage of initial development and it competes with the traditional information system based on a centralized data-base. The Blockchain-based solutions have significant drawbacks, in particular, the speed of information update, high requirements for storage space. The advantage of decentralization is also a significant drawback because the system has no a centralized structure that could be a moderator in conflicts [12]. The next drawback is that the Block-chain-based system consumes a lot of electric energy. This leads to the low economic feasibility of the blockchain technology. In the future, the situation will change and the main advantage - the reliability of information storage - will be able to outweigh these drawbacks and create the new effective smart transport systems with block-chains.

\section{RESULT AND DISCUSSION}

\section{A. Decentralized smart transport systems based on Blockchain technology}

Blockchain technology can be used to create a secure and reliable decentralized intelligent transport system. However, from a research point of view, it is necessary to point out some problems which should be resolved for using the blockchain in the transport sector. In this section, we consider these problems [13-19] and briefly discuss potential areas of further research in Fig. 1.

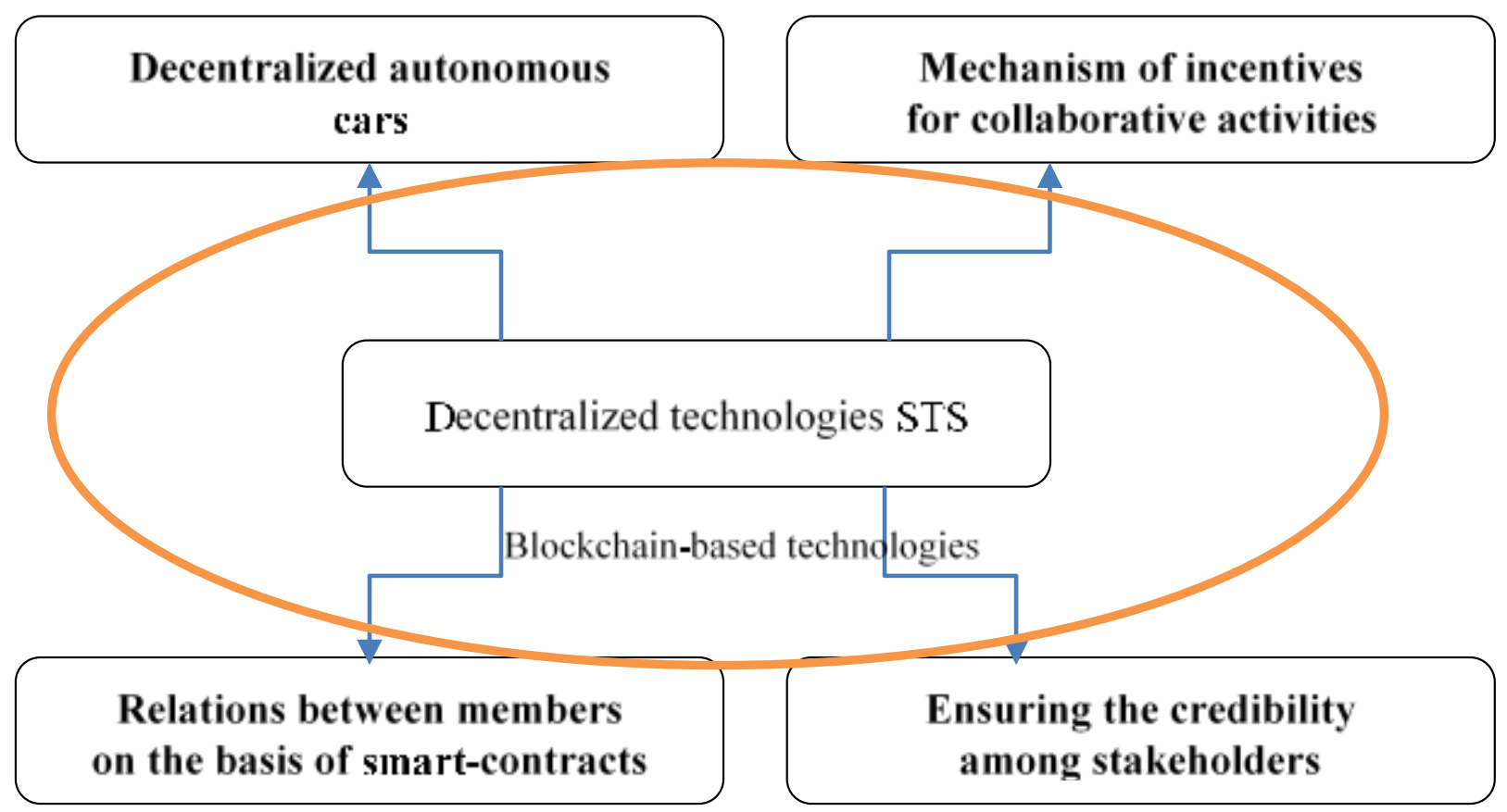

Fig. 1. Research areas of decentralized technologies in ITS 
Decentralized autonomous cars. Autonomous cars have long been a promising area for urban logistics and it is an ideal object for using decentralized networks [20]. The main components of Blockchain technology are peer-to-peer systems with distributed coordination based on consensus and financial rewards for maintenance of the network. Such system is a good analogy and a good way of modeling the complex transport network. Each node of transport network (an IoT device, a vehicle, or other object in the network) can be considered as an agent in a blockchain network. Nodes can communicate directly with each other by decentralized applications (DAPPS), create decentralized autonomous organization (DAO), and at the macro level they form decentralized autonomous systems (DAS).

It is possible to create the macro-level models, describing the individual behavior of transport agents and the interaction between the autonomous agents and the self-organizing agents at the macro level of adaptive DAO and DAS systems [21].

Mechanism of incentives for collaborative activities. The task of consensus among competing agents can be resolved by collaborative activities of vehicles in smart transport system (STS). Each node is a competing agent with its own set of goals, so mechanisms which help to reach the consensus between participants should be designed so that agent's individual behavior aimed at maximizing of its own revenues comes along with the system goals and provides the security and reliability of the system [22]. Such model can be applied to aggregate all computing resources of STS for solving complex transport problems, for example, the problem of effective management and control of transportation in real time.

Ensuring the credibility among stakeholders. The credibility of each participant, based on the Blockchain technology, plays an important role in the decentralized systems. Credibility environment allows one to use different scenarios, including peer-to-peer trading, secure payment and secure information exchange. When trust is guaranteed by the system architecture, crypto stability, validation mechanisms and it can be considered as a software trust. We can significantly reduce the structural complexity, social complexity for money and assets exchange between companies. For example, based on peer-to-peer trust, any cars can be sold or directly registered through the internal Blockchain-based applications without using the centralized systems.

Relations between members on the basis of Smartcontracts. Smart contract is a key concept of blockchain, which causes the transformation of static data into the algorithmic constructions. These algorithms allow one to create the high-level business logic and software for using in autonomy application. The Smart-contracts also significantly reduce the structural complexity of the system and reduce the influence of human factor. Systems built on the Smartcontracts can act as software agents of the creator. Therefore, the implementation of specific smart contracts is an important task, as well as the creation of systems for management and its control based on smart contracts. Despite the fact that the blockchain technology demonstrates strong resistance to security attacks, the encryption mechanisms need to be strengthened for using in STS with a large number of connected devices for protection of the system from a $51 \%$ attack.

\section{B. Balancing interests in a smart transport system with the blockchain-based technology}

Modern approaches of studying the smart transport systems can be presented as a universal model of interactions between some stakeholders [23-25]. We identified the participants and links between them; also we defined their interests and goals [26].

Researchers point out that in the smart transport system, the central element is a city resident who can have different roles: the role of the passenger, the role of a resident who doesn't use transport, but has its negative impact, or in the active role as the car driver. The smart transport system should ensure the social justice in the distribution and utilization of the city's transport resources among all participants.

Out representation of the smart transport system is based on the definition of these four stakeholders, each of them has his own interests, and establishing the relationship between which determines by the main trend of development Fig. 2.

The key subject of the social system is the consumer, in this case, a passenger who has certain needs and is able to satisfy needs.

The demand generates supply, so the second subject is an agent which is able to satisfy the needs of the consumer. The relationship between them requires the external environment with a special regulator in most cases it is the state government [27]. Regulation is necessary to equalize the ability of participants to satisfy their interests in the current institutional system.

Participants are competitors or antagonists, so each participant can belong to one or more groups, and his primary desire is to pursue self-interest and minimizing infringement. Finding a balance of interests is an important task to ensure the stable development of the STS, and the key problem is the formation of an institutional environment which allows participants to satisfy their needs, provide necessary services and make a profit.

The smart transport system can be divided into the following entities; each of them has its own benefits from the implementation of the blockchain technology:

- city residents, who can have two roles: transport passengers and drivers, who consumes transport services when move from point A to point B;

- city residents, who do not use transport, but they experience negative consequences from the transport system;

- the transport company, which provides transport services;

- the regulator, represented by the state, who protects the rights of consumers and other city residents and creates institutional environment for the transport companies. 


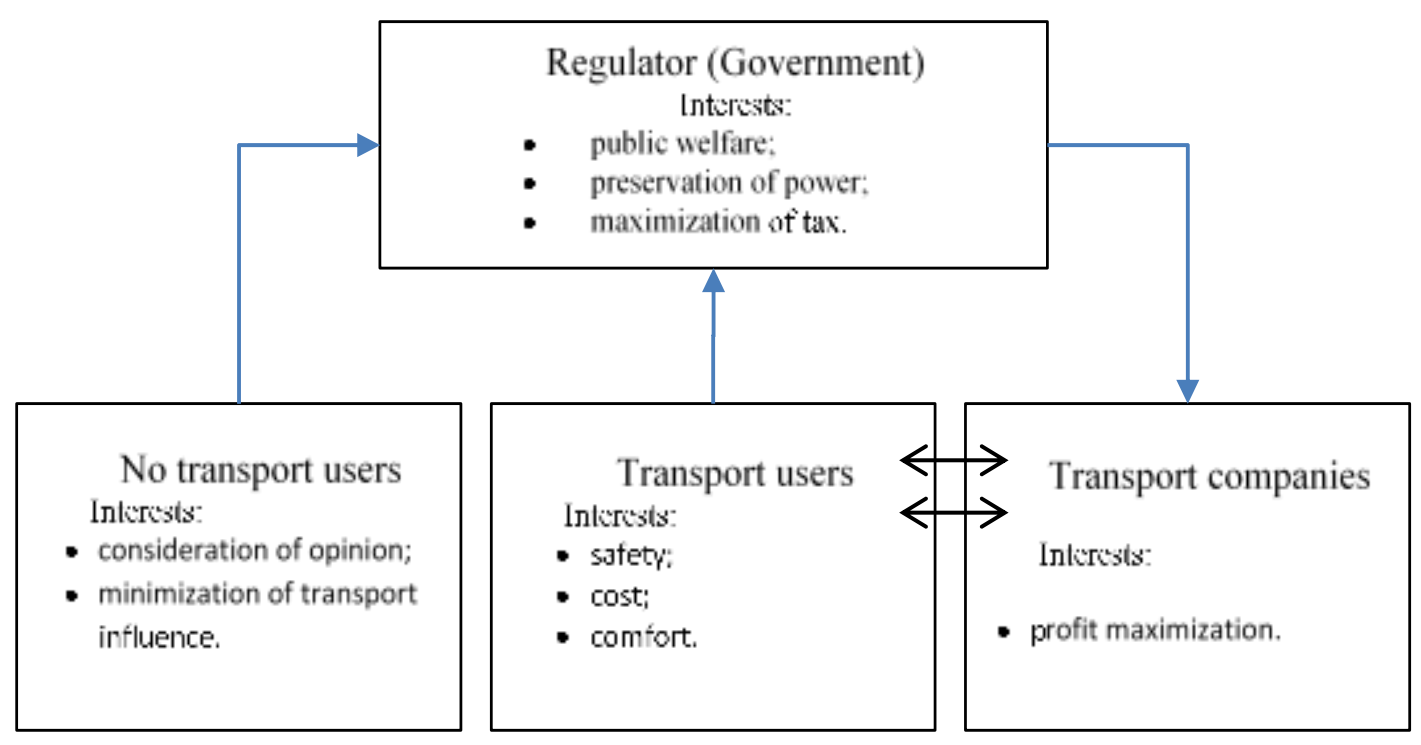

Fig. 2. The balance of interests of participants of smart transport system

The basic needs of transport users lie in the sphere of convenient access to transport services that meet the safety requirements of affordable comfort level. Each of these needs can be studied in more depth and considered, for example, by sociological survey methods. Such methods allow to identify the valid structure of urban transport system, taking into account the current demographic composition and the satisfaction degree of passengers about the existing transport system, and to establish directions of future development. Implementation of the blockchain-based technology will ensure the security and efficiency of public and private transport, allow one to create effective fare collection system and additional electronic services.

City residents who are not passengers but are affected by the transport system are the most difficult object for investigation. It is difficult to define their interests. In general, they want to reduce the influence of urban transport on their life, and think that transport should have minimal impact on the environment, etc. At the same time, some researchers show a high inconsistency in their interests and point out that often their interests are only a set of individual interests in contrary to the interests of transport users. For example, they want to ban parking in the yard. Implementation of the Blockchain technology for them will increase the availability of transport services without having their own transport (car sharing), reduce the pollution, reduce the amount of transport in the city and provide more efficient using of it.

Traditionally, in the sector of public transport there are different forms of ownership and governance of company, in particular: state, private or mixed.

But there is no difference between them, the form only changes the main source of financial flows and the degree of funding from the state for supporting the social services. In a regular situation, the interests of these companies is to optimize the transportation process and increase the business efficiency. The Blockchain-based technology allows increasing the efficiency of transportation process, expanding the number of users and the security of financial transactions.

The state interests are expressed by an elite group of regional or municipal government, whose members have certain political interests and want to hold power as long as possible. Public transport is a very important instrument of political struggle, especially for attracting investment resources, so there is a certain inconsistency in the government actions. It is common sense that the state interests should ensure the equitable use of resources, assure the stability and sustainability of transport system, reduce the costs, and expand the sphere. The blockchain-based technology will ensure the reliability of information system, expand the number of transport services, increase the security of financial transactions (Table I).

TABLE I. THE BENEFITS OF IMPLEMENTATION BLOCKCHAIN-BASED TECHNOLOGY FOR STAKEHOLDERS

\begin{tabular}{|l|l|l|}
\hline \multicolumn{1}{|c|}{ Category } & \multicolumn{1}{c|}{$\begin{array}{c}\text { Needs for using the } \\
\text { blockchain-based technology }\end{array}$} & $\begin{array}{c}\text { The degree of } \\
\text { interest in using } \\
\text { the blockchain- } \\
\text { based technology }\end{array}$ \\
\hline $\begin{array}{l}\text { City residents } \\
\text { who are actively } \\
\text { using transport } \\
\text { system }\end{array}$ & $\begin{array}{l}\text { the need for security, efficient use of } \\
\text { public and private transport, an } \\
\text { effective fare collection system, the } \\
\text { availability of electronic services }\end{array}$ & High \\
\hline $\begin{array}{l}\text { City residents } \\
\text { who } \\
\text { requires little } \\
\text { use of transport } \\
\text { services }\end{array}$ & $\begin{array}{l}\text { the need to increase the availability } \\
\text { of transport services, without } \\
\text { owning transport (car sharing), } \\
\text { reduce pollution from transport, } \\
\text { reduce the amount of transport in the } \\
\text { city providing more efficient use }\end{array}$ & Average \\
\hline $\begin{array}{l}\text { Transport } \\
\text { companies }\end{array}$ & $\begin{array}{l}\text { the need to increase the efficiency of } \\
\text { transport, increase the number of } \\
\text { users, increase the security of } \\
\text { financial transactions }\end{array}$ & Average \\
\hline Government & $\begin{array}{l}\text { The need to ensure the reliability of } \\
\text { the collection of information on the } \\
\text { use of transport, to expand the } \\
\text { number of transport services in the } \\
\text { city, to increase the security of } \\
\text { financial transactions }\end{array}$ & High \\
\hline
\end{tabular}


The applied part of our study is devoted to the analysis of the company that plans or has already come to the initial placement of its crypto assets and operates in the field of urban public transport. Primary placement of cryptocurrency or Initial Coin Offer (ICO) [28-31] is an important type of funding using cryptocurrencies. Such activities are aimed at creating start-up projects that solve a certain problem with the help of cryptocurrency technologies. The organizers of ICO create a fund which implement their project by the model of crowdfunding, then actively advertise their project and raise money. The idea of ICO is quite rational as it allows ensuring a high degree of investment security without external guarantees, using decentralization mechanisms.

There are many promising projects that will make profit for their investors in the future, but there are some projects which were created only for fraudulent purposes (Scam projects). Mechanisms of ICO are still evolving. Therefore, in this area, there is no effective system of project analysis to ensure economic security of investments.

There are different categories of scam projects depending on their complexity. The creators of simple projects are developing a commercial proposal based on cryptocurrencies idea and sending it through all possible communication channels to different people. In 2017, the sharp growth number of such projects led to that many advertising platforms and searching engines in the Internet refused to place advertising information about any cryptocurrency projects.

The medium complexity scam projects are not supported by real technology and the creators do not make a good project, but they think that the faster they come to the market the more chances they have to get the investments for the project. Companies collect money, but they have no a real product, so they cannot earn the income. Many of such companies have closed by the middle of 2018 .

The complex scam projects are projects that initially attracted highly qualified specialists. Recognizing scam in such projects is very difficult because they look very attractive and their creators are doing everything to hide any fraudulent activity [29].

Based on the analysis of existing approaches [29, 30, 32], we developed an algorithm that allows one to make verification of projects and classify them into various categories by their risk. The analysis allows minimizing the loss of funds from scam project (Fig. 3).

TABLE II. RISK ANALYSIS IN ICO PROJECT

\begin{tabular}{|l|l|l|l|}
\hline \multirow{2}{*}{ Product feature } & \multicolumn{3}{|c|}{ Using internal cryptocurrency } \\
\cline { 2 - 4 } & $\begin{array}{c}\text { No internal } \\
\text { cryptocurrency }\end{array}$ & $\begin{array}{l}\text { Reasonable use } \\
\text { of internal } \\
\text { cryptocurrency }\end{array}$ & $\begin{array}{c}\text { The need for using } \\
\text { internal } \\
\text { cryptocurrency is } \\
\text { questionable }\end{array}$ \\
\hline $\begin{array}{l}\text { Fully functional } \\
\text { and new for the } \\
\text { market product }\end{array}$ & $\begin{array}{l}\text { Low investment } \\
\text { risk }\end{array}$ & $\begin{array}{l}\text { Low } \\
\text { investment risk }\end{array}$ & $\begin{array}{l}\text { High investment } \\
\text { risk }\end{array}$ \\
\hline $\begin{array}{l}\text { Existing product } \\
\text { on the market }\end{array}$ & $\begin{array}{l}\text { Low investment } \\
\text { risk }\end{array}$ & $\begin{array}{l}\text { Acceptable } \\
\text { investment risk }\end{array}$ & $\begin{array}{l}\text { High investment } \\
\text { risk }\end{array}$ \\
\hline $\begin{array}{l}\text { The absence of a } \\
\text { real product }\end{array}$ & $\begin{array}{l}\text { High } \\
\text { investment risk }\end{array}$ & $\begin{array}{l}\text { High } \\
\text { investment risk }\end{array}$ & $\begin{array}{l}\text { High investment } \\
\text { risk }\end{array}$ \\
\hline
\end{tabular}

In accordance with the proposed algorithm, there are some steps to check the project. The first step is to check the existence of the ICO organizer company. It is necessary to establish contact with them in any possible ways through various communication channels. An honest organizer is interested in communication with the investors. The communication allows them to look at the project from the outside and potentially increase the volume of investments and the number of investors. If such communication could not be established or the organizers responses are suspicious, and they do not disclose the essence of the project, the project is very risky (Table II).

\section{Blockchain-based projects in smart transport system}

Blockchain is actively implemented in many industries, including the sharing economy.

In 2017 the McKinsey survey [33] showed that $67 \%$ of respondents in US prefer to use their own cars instead of cars rented through mobile applications. More than $63 \%$ are not interested in using rented cars at all, even if these services were free of charge.

At the same time, there is a stable category of people who are determined to share cars and, in the future, they plan to significantly increase the number of trips in this way. Also, some researchers show that the range of transport modes with car sharing is quite limited. The patterns of behavior for the young drivers show that they are interested in using the car sharing and have a negative attitude to investing in the purchase of a personal car [33].

The positive forecasts of development in this sphere significantly intensify the activities of small technology companies, which launch startups in transport sector employing the blockchain-based technology. We examined internet sites of these companies, and analyzed some existing publications [33]. We compared some innovative companies that have already entered the market of smart mobility with the Blockchain-based technologies.

Mixrent. Mixrent has developed an information system based on BlockChain technology that brings together vehicle owners and vehicle users into a community that simplifies the process of renting vehicles. Information about all transactions that are performed is stored in a distributed database that cannot be tampered or modified.

The system has the ability to compare different offers according to user-defined criteria; it allows saving up to $25 \%$ of rent price in comparing with a traditional rent company. Users of the system have opportunity to get a discount up to $35 \%$ as a cashback, if they use the internal MIX tokens for payment. The system is implemented as a beta version and is already working. It has more than 12,000 participants, involved more than 9,500 transport units, system works in different cities of the United States, Russia, Canada, Mexico. Soon the project will enter to the markets of Australia and South Korea.

BitCab. The company is a pioneer of carsharing on blockchain-based technology. They have developed an ecosystem 
of carsharing, they have own methods of ensuring user loyalty and a technological system for attraction of users. Low tariffs, security of transactions for users, as well as an effective rating system are the advantages of this project. Disadvantages are absence of a normal detailed White paper that describe the prospects of company and they have no ICO date.

Darenta. The company presents a platform for carsharing with the ability of sending and receiving payments with cryptocurrencies. The platform uses blockchain technology and smart contracts for people who want to rent or lease a car. The disadvantage of the project is the underdeveloped community and low level of token development. Currently, this is one of the most successful projects in the field of carsharing, which implemented a mechanism for the sale of successful tokens. They went to several crypto exchanges, including the Coinmarketcap exchange.
Drivero. The platform that implements a system of carsharing with geolocation based on blockchain technology. The advantages of these projects are the possibility of using wide range of vehicles and reducing their deficit in some area point. Unfortunately the project has not received a good development due to diseases and its founder and is experiencing serious problems with entering to the market

Gitto Project Web. Platform for car rental on the model of car sharing uses cryptocurrency. The company offers an opportunity to earn money for crypto investors. The company considers its activities as an experiment and is looking for various options for implementing blockchain technology in the transport sector. ICO has been postponed several times and has not yet been conducted; currently the project site is not working, and the developers do not respond to e-mail.

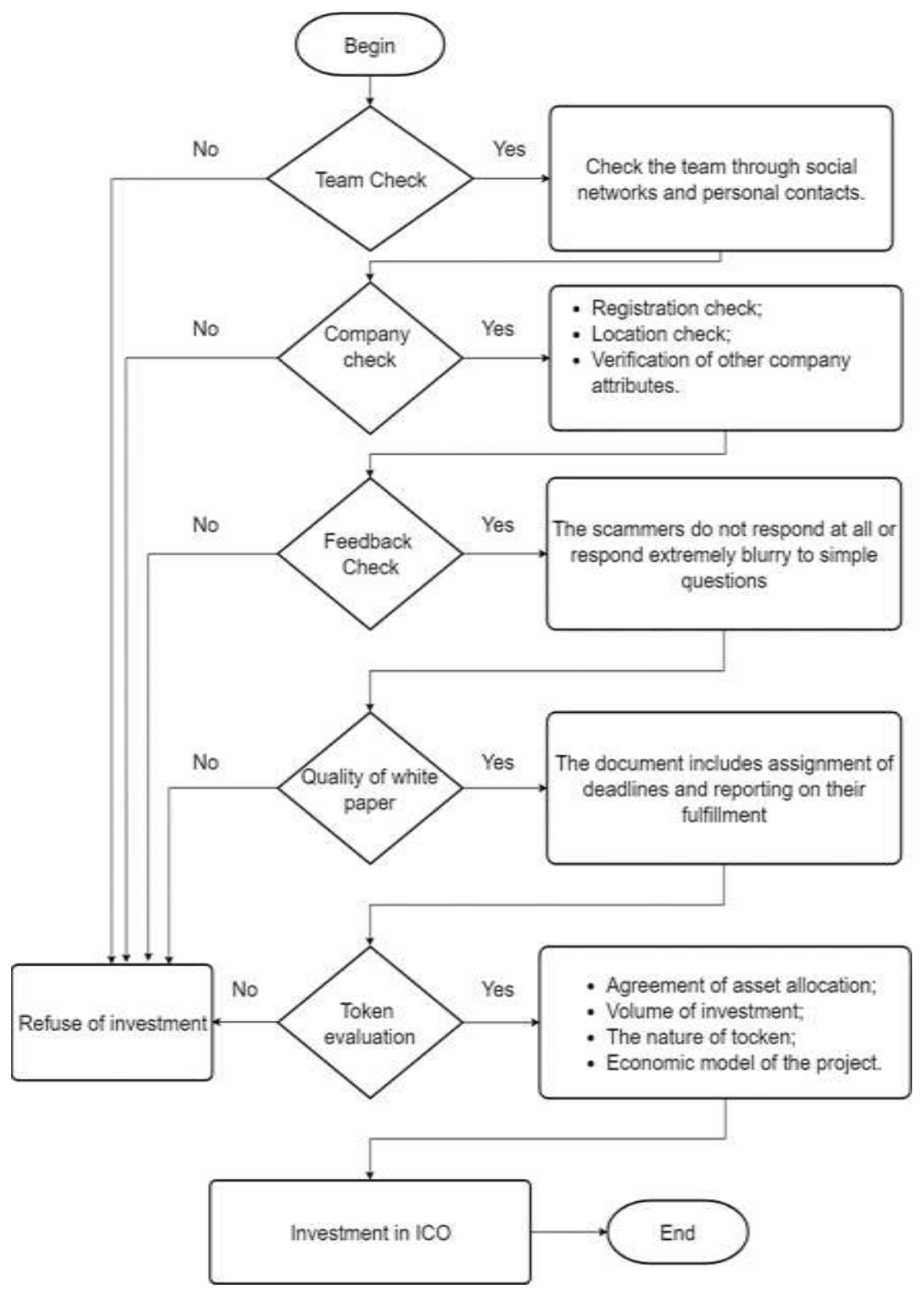

Fig. 3. Risk of investment in ICO validating algorithm 


\section{CONCLUSION}

We have analyzed the projects in accordance with the algorithm and determined the risk of investment in each of the described projects. Table III presents the results of the analysis, as well as our final recommendation on investing in the project.

TABLE III. THE RESULTS OF RISK ANALYZING

\begin{tabular}{|l|l|l|l|l|l|}
\hline $\begin{array}{c}\text { Project } \\
\text { title }\end{array}$ & Team & $\begin{array}{c}\text { Existence of } \\
\text { a legal entity }\end{array}$ & $\begin{array}{c}\text { Internal } \\
\text { cryptocurr } \\
\text { ency }\end{array}$ & $\begin{array}{c}\text { Quality of } \\
\text { ICO white } \\
\text { paper }\end{array}$ & $\begin{array}{c}\text { Investment } \\
\text { recommendat } \\
\text { ions }\end{array}$ \\
\hline Mixrent & Yes & Exists & Yes & High & Yes \\
\hline BitCab & Yes & Exists & No & Medium & No \\
\hline Darenta & Yes & Exists & Yes & High & Yes \\
\hline Drivero & Yes & Exists & No & Medium & No \\
\hline $\begin{array}{l}\text { Gitto } \\
\begin{array}{l}\text { Project } \\
\text { Web }\end{array}\end{array}$ & No & No & No & Low & No \\
\hline
\end{tabular}

We give a recommendation of investment only for two projects: Mixrent and Darenta.

\section{References}

[1] D. Sümmermann, C. Öge, M. Smolenski, G. Fridgen, A. Rieger, "The open mobility system - executive summary our vision of the future: seamless mobility as a service", May 2017, Retrieved from: https://www.omos.io/wp-

content/uploads/whitepaper/OMOS_concept_paper.pdf.

[2] N.B. Aletà, C.M. Alonso, R.M. Ruiz, "Smart Mobility and Smart Environment in the Spanish cities", Transp. Res. Procedia, vol. 24, pp. 163-170, 2017.

[3] B. Volker, D. Léan, M. Webb, C. Aoun, "Urban mobility in the smart city age", 2013, Retrieved from: https://www.arup.com/perspectives/ publications/research/section/urban-mobility-in-the-smart-city-age

[4] I. Kubáč, "The application of internet of things in logistics", Transp. \& Logistics: the Int. J., vol. 16, pp. 9-18, June 2016.

[5] H. Atlam, A. Alenezi, M. Alassafi, G. Wills, "Blockchain with Internet of Things: Benefits, Challenges, and Future Directions", Int. J. of Intellig. Syst. and Applicat., vol. 10, no. 6, pp. 40-48, June 2018.

[6] M. Conoscenti, A. Vetro, J. De Martin, "Blockchain for the Internet of Things: A systematic literature review", AICCSA, pp. 16, November 2016 [The Third Int. Symp. on Internet of Things: Systems, Management and Security, 2016].

[7] J. Gehrke, O. Herzog, H. Langer, R. Malaka, R. Porzel, T. Warden, "An Agent-based Approach to Autonomous Logistic Processes", KI Künstliche Intelligenz, vol. 24, pp. 137-141, 2010.

[8] M. Hülsmann, B. Scholz-Reiter, K. Windt, Autonomous Cooperation and Control in Logistics. Berlin: Springer Berlin Heidelberg, 2011.

[9] D. Namot, O. Pocusayev, V. Kuprijanovskij, A. Akimov, "Applications blockchain on transport”, Int. J. Open Inf. Technol, vol. 5, no. 12, pp. 130-134, 2017.

[10] B. Vitaris, "Blockchain in Trucking Alliance Seeks to Revolutionize the Transport Industry", 29 August 2017. Retrieved from https://bitcoinmagazine.com/articles/blockchain-trucking-alliance-seeksrevolutionize-transport-industry/.

[11] M. Atzori, "Blockchain-Based Architectures for the Internet of Things: a Survey", January 2017, Retrieved from: https://ssrn.com/abstract= 2846810 or http://dx.doi.org/10.2139/ssrn.2846810

[12] M. Asmolova, S. Dedov, "The algorithm to ensure and implement the strategy of the effective management of innovation processes", Bull. of the Voronezh State Univer. of Engineer. Technol., vol. 80, no. 4, pp. 436-440, 2018.

[13] Z. Zheng, S. Xie, H. Dai, H. Wang, "Blockchain challenges and opportunities: A survey", Int. J. of Web and Grid Services, vol. 14, no. 4 , p. 352, October 2018 .
[14] K. Christidis, M. Devetsikiotis, "Blockchains and Smart Contracts for the Internet of Things", IEEE Access, vol. 4, pp. 2292-2303, 2016.

[15] Y. Yuan, F.-Y. Wang, "Towards blockchain-based intelligent transportation systems", IEEE 2016, pp. 2663-2668, 2016 [19th Int. Conf. on Intelligent Transportation Systems, 2016].

[16] J. Sun, J. Yan, K. Zhang, "Blockchain-based sharing services: What blockchain technology can contribute to smart cities", Financ. Innov., vol. 2, no. 26, pp. 3-9, 2016

[17] M. Friedlmaier, A. Tumasjan, I. Welpe, "Disrupting Industries With Blockchain: The Industry, Venture Capital Funding, and Regional Distribution of Blockchain Ventures", Ssrn, 2016 [The 51st Annual Hawaii Int. Conf. on System Sciences (HICSS), January 2018], Retrieved from: https://ssrn.com/abstract=2854756 or http://dx.doi.org/ $10.2139 / \mathrm{ssrn} .2854756$

[18] E. Hofmann, U. Strewe, N. Bosia, "Concept-Where Are the Opportunities of Blockchain-Driven Supply Chain Finance?”, 2018. Retrieved from: http://link.springer.com/10.1007/978-3-319-62371-9_5.

[19] S. Jeschke, "Towards Logistics 4.0 - Distributed Systems with Decentralized Control Paradigms", 2015. Retrieved from: http://www.ima-zlw-ifu.rwthaachen.de/fileadmin/user_upload/Institutscl

[20] V. Tregubov, E. Morozov, "Innovative logistic technologies of intraurban transport movements in urbanistic systems", Innovat. activity, vol. 3, no. 38, pp. 43-51, 2016.

[21] S. Chowdhury, Y. Hadas, V. Gonzalez, B. Schot, "Public transport users' and policy makers' perceptions of integrated public transport systems", Transp. Policy, vol. 61, pp. 75-83, 2018.

[22] E. Karpunina, E. Yurina, I. Kuznetsov, A. Dubovitski, "Growth potential and economic security threats in terms of digital economy ecosystem", Vision 2020: Education Excellence and Management of Innovations through Sustainable Economic Competitive Advantage, pp. 2669-2678, April 2019 [The 33nd Int. Business Information Management Association (IBIMA) conf., Granada, Spain, 2019].

[23] McKinsey Institute, "Elements of success: Urban transportation systems of 24 global cities", June 2018. Retrieved from: https://www.mckinsey.com/ /media/McKinsey/Business\%20Functions/ Sustainability/Our\%20Insights/Elements\%20of\%20success $\% 20 U$ rban\% 20transportation $\% 20$ systems $\% 20$ of\%2024\%20global\%20cities/Urbantransportation-systems_e-versions.ashx

[24] V. Thao, P. Wegelin, W. von Arx, "Are statutory passenger watchdogs effective in representing passenger interests in public transport?", Transp. Policy, vol. 58, pp. 1-9, 2017.

[25] A. Evseeva, "Novaya gorodskaya mobil'nost': tendencii razvitiya transportnyh system", Gosudarstvennoe upravlenie. Elektronnyj vestnik, no. 59, pp. 238-266, 2016.

[26] J. Conley, "Blockchain and the Economics of Crypto-Tokens and Initial Coin Offerings", Vanderbilt University Department of Economics Working Papers, VUECON-17-00008. Retrieved from: http://www.accessecon.com/Pubs/VUECON/VUECON-17-00008.pdf

[27] Y. Salikov, I. Logunova, I. Kablashova, "Trends in human resource management in the digital economy", Bull. of the Voronezh State Univer. of Engineer. Technol., vol. 81, no. 2, pp. 393-399, 2019.

[28] U. Chohan, "Initial Coin Offerings (ICOs): Risks, Regulation, and Accountability", in: S. Goutte, K. Guesmi, S. Saadi (eds) Cryptofinance and Mechanisms of Exchange. Contributions to Management Science, Springer, Cham, 2019, pp. 165-177.

[29] M. Anson, "Initial Coin Offerings: Economic Reality or Virtual Economics?", J. Priv. Equity, vol. 21, pp. 41-52, 2018.

[30] L. Arnold, M. Brennecke, P. Camus, G. Fridgen, T. Guggenberger, S. Radszuwill, "Blockchain and Initial Coin Offerings: Blockchain's Implications for Crowdfunding", in H. Treiblmaier, R. Beck (eds) Business Transformation through Blockchain, Palgrave Macmillan, Cham, 2018, pp. 233-272.

[31] V. Tregubov, V. Agafonova, "Risks of participants of innovative financial systems in the cryptoeconomy and ways of their minimization", Innovat. activity, vol. 1, no. 44, pp. 58-67, 2018.

[32] McKinsey\&Company, "How shared mobility will change the automotive industry”, 2017. Retrieved from: https://www.mckinsey.

[33] K. Bezverhi, "10 Most Remarkable Transport Sharing Startups on Blockchain”, September 2018. Retrieved from: https://hackernoon.com/ 10-most-remarkable-transport-sharing-startups-on-blockchain$227 \mathrm{fdc} 37 \mathrm{a} 908$ 